\title{
Editorial: The First Five Years (2013-2017) of Life: The Excitement of Biology
}

\author{
Jorge A. Santiago-Blay ${ }^{1}$
}

This is my annual summary of the major developments of Life: The Excitement of Biology, emphasizing 2017. I began writing this short essay in August 25, 2018, right after receiving abysmally bad customer service at a local store. After dejectedly returning to my car, I listened to the TED Radio Hour. There, someone from the Rhode Island School of Design said, "whenever one sees duct tape, there is an opportunity for design". Those two juxtaposed experiences made me remember why I created Life: The Excitement of Biology in 2012.

\section{Main Accomplishments}

1. Indexing and Referencing. Life: The Excitement of Biology continues to be indexed and its published articles detecteded by Biosis, Biological Abstracts, CAB Abstracts, Google Scholar, and Research Gate.

2. Increased Internationalization. More scholars joined the Board of Editors of Life: The Excitement of Biology during 2017. Currently, the board has over 100 members representing over 40 countries worldwide.

3. "Responsive" Presence via Social Media. Life: The Excitement of Biology retains a strong digital presence through, WordPress, its digital carrier at https://blaypublishers.com. Also, $\boldsymbol{L E} \boldsymbol{B}$ maintains a regular presence, particularly through email, Facebook, LinkedIn, and Twitter, among others.

4. Constantly Improving. Authors, reviewers, subscribers, and members of the boards of Life: The Excitement of Biology continue suggesting improvements to the journal many of which we have incorporated. This editor insists that all scientific papers submitted to $\boldsymbol{L E} \boldsymbol{B}$ be peer-reviewed while colleagues doing the reviews are encouraged to be careful, contructive, and as fast as possible. It is essential the authors take at heart the suggestions of reviewers and do not ignore alternative scientific explanations for the events they are trying to explain.

All of these continue helping $\boldsymbol{L E} \boldsymbol{B}$ gain visibility among the communities of scholars and the broader public. The support of Wolf Printing of York,

${ }^{1} 217$ Wynwood Road, York, Pennsylvania 17402 USA. E-mail: blayjorge@gmail.com

DOI: 10.9784/LEB6(1)SantiagoBlay.01

Electronically available on October 31, 2018. Mailed on October 31, 2018. 
Pennsylvania (USA), printers of the hard copy version of Life: The Excitement $\boldsymbol{o f}$ Biology as well as WordPress, carrier of the digital version of $\boldsymbol{L E B}$ and their friendly and helpful online staff members deserve a special recognition.

Please, feel free to spread the word about Life: The Excitement of Biology and its high quality, fast publication, and helpfulness. I hope all of you join me in a wonderful voyage of discovery during 2018 and years to come.

Sincerely and gratefully,

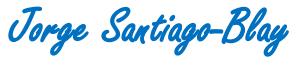

Jorge Santiago-Blay, Ph.D.

Editor-in-Chief, Life: The Excitement of Biology

E-mail: blaypublishers@gmail.com

WordPress: Life-The Excitement of Biology, LinkedIn: Jorge Santiago-Blay

Facebook: Jorge A. Santiago-Blay, Twitter: @blayjorge

$$
\text { *** }
$$

\section{Erratum}

Ríos-Franceschi and Joglar wish to correct a typo on the initials of the first author of one of the works listed in the Literature Cited of Ríos-Franceschi, A. and R. L. Joglar. 2017 "2016". Harmonics: Rediscovering Eleutherodactylus Vocalizations. Life: The Excitement of Biology 5(4):173-180.

The correct initials of author Benevides are. J. R. The corrected citation now reads:

Benevides Jr., J. R. and W. J. Mautz. 2013. Temporal and spectral characteristics of the male Eleutherodactylus coqui two-note vocalization in Hawaii. Bioacoustics 23(1):29-38. https://doi.org/10.1080/09524622.2013.805308 . 